\title{
GLUTAMATE DECARBOXYLASE IMMUNOREACTIVITY IN THE HIPPOCAMPUS OF THE CAT: DISTRIBUTION OF IMMUNOREACTIVE SYNAPTIC TERMINALS WITH SPECIAL REFERENCE TO THE AXON INITIAL SEGMENT OF PYRAMIDAL NEURONS ${ }^{1}$
}

\author{
P. SOMOGYI, ${ }^{*}, \S$, A. D. SMITH,$\ddagger^{2}$ M. G. NUNZI, $\S$ A. GORIO,$\S$ H. TAKAGI, ${ }^{*, 3}$ AND J. Y. WU $\|$ \\ ${ }^{*} 1$ st Department of Anatomy, Semmelweis Medical Achool, Tuzolto u. 58, 1450 Budapest IX, Hungary; $\ddagger$ University \\ Department of Pharmacology, South Parks Road, Oxford, OX1 3QT, United Kindgom; \$Fidia Research Laboratories, 35031 \\ Abano Terme, Padova, Italy; and \|| Department of Cell Biology, Baylor College of Medicine, Houston, Texas 77030, U. S. A.
}

Received November 8, 1982; Revised January 24, 1983; Accepted February 8, 1983

\begin{abstract}
Golgi-impregnated and gold-toned preparations of cat hippocampus were studied under the light and electron microscope in order to characterize synapses in contact with the axon initial segments of pyramidal neurons. The initial segment of the axon emits spine-like appendages and it was sometimes seen to be in apparent contact with thin varicose fibers that climbed along it. The latter type of varicose axon terminal segments occurred at the base of pyramidal neurons in all regions of the hippocampus and in the subiculum: they are 20 to $40 \mu \mathrm{m}$ long, contain 3 to 15 varicose swellings, and are interconnected by thin horizontal or arcadic fibers. It was established by electron microscopy of gold-toned material that light microscopically identified varicosities of these terminal segments were in symmetrical synaptic contact exclusively with axon initial segments; four of the initial segments in the CA1 region could be traced back to pyramidal neurons. Thus the pyramidal cell of the cat hippocampus receives input along its axon initial segment from boutons that probably originate from axoaxonic cells of the type found previously in the cerebral cortex and monkey hippocampus.

Antiserum to glutamate decarboxylase was used to study the distribution and nature of cells and processes that bound the antiserum. Several different types of immunoreactive cell bodies were found in all layers in regions CA1 to CA3, suggesting that many kinds of GABAergic interneurons are present in the hippocampus. Fibers and varicosities that were immunoreactive for glutamate decarboxylase were also found in all layers. The most conspicuous patterns formed by immunoreactive varicosities were in the pyramidal cell layer, where they occurred as pericellular nets around all pyramidal neurons. Immunoreactive processes or varicosities also followed both apical and basal dendrites, but a very high density of immunoreactive varicosities was seen around fine (diameter 2 to $4 \mu \mathrm{m}$ ) tube-like structures that could sometimes be seen to lie at the base of pyramidal neurons. Electron microscopic analysis of immunoreactive structures that had first been identified in the light microscope established that the varicosities outlining such tube-like structures were boutons in symmetrical synaptic contact with the axon initial segments of pyramidal neurons; the other immunoreactive varicosities were boutons in symmetrical contact with cell bodies and apical and basal dendrites of pyramidal neurons. Detailed study of 19 axon initial segments showed that immunoreactive boutons occur most commonly along more distal parts of the initial segment, where they almost completely surround the axon and form symmetrical synapses not only along the main axon, but also with its spines. Since the glutamate decarboxylase-immunoreactive boutons comprised $92 \%$ of all symmetrical synaptic boutons along the initial segments, it was concluded that the axoaxonic cell uses $\gamma$-aminobutyrate as its transmitter.

It is suggested that the pyramidal neuron receives input from more than one type of GABAergic
\end{abstract}

\footnotetext{
${ }^{1}$ We are grateful to Mrs. K. Boczko and Miss S. Thomas for excellent technical assistance. This work was supported by the Wellcome Trust, the Royal Society, the E. P. A. Cephalosporin Trust, the International Cultural Institute (Budapest), the Japanese Society for the Promotion of Sciences, the Hungarian Academy of Sciences, and Grants NS 13224 and EY 03909 from the National Institutes of Health.
}

\footnotetext{
${ }^{2}$ To whom correspondence should be addressed.

${ }^{3}$ Visiting Scientist from the Department of Neuroanatomy, Institute of Higher Nervous Activity, Osaka University Medical School, 4-3-57 Nakanoshima, Kitaku, Osaka, Japan. Scholar of Herbert von Karajan Neuroscience Research Trust.
} 
interneuron, but that the input to the axon initial segment is mainly from the axoaxonic cell. If this is so, then such a powerful and specific input from a GABAergic neuron must have important implications for the control of the output of pyramidal neurons.

Electrophysiological studies have shown that inhibitory postsynaptic potentials in hippocampal pyramidal cells of the cat are due to the activation of interneurons (Kandel et al., 1961; Spencer and Kandel, 1961a; Knowles and Schwartzkroin, 1981). Almost all pyramidal cells in the cat show such inhibitory potentials, which are thought to originate as a result of synaptic input "on or close to the pyramidal cell somata" (Andersen et al., 1964A). It has been proposed (Andersen et al., 1963, 1964a, b) that the basket cell described in Golgi studies (Ramón y Cajal, 1911, 1968; Lorente de Nó, 1934) is the source of the inhibitory postsynaptic potential (see reviews by Andersen et al., 1969; Andersen, 1975). The findings that $\gamma$-aminobutyrate (GABA) causes inhibition of hippocampal pyramidal cells (Biscoe and Straughan, 1966), that this inhibition and the synaptically evoked inhibitory potential are both blocked by bicuculline (Curtis et al., 1970, 1971), and that the intracellular reversal potential for GABA is the same as that for the inhibitory postsynaptic potential (Ben-Ari et al., 1981) have led to the view that the transmitter of the inhibitory interneurons is GABA (Storm-Mathisen, 1977). Glutamate decarboxylase (GAD), the enzyme that catalyzes the synthesis of GABA, has been found to be present in pericellular varicosities in the pyramidal cell layer (Barber and Saito, 1976; Ribak et al., 1978); such varicosities have been shown by electron microscopy to be boutons in synaptic contact with the cell bodies of pyramidal cells (Ribak et al., 1978). Thus there is a lot of circumstantial evidence consistent with the view that basket cells produce GABA-mediated inhibition. However, the discovery of a new type of interneuron in the hippocampus, the axoaxonic cell, which makes symmetrical synapses exclusively on the strategically important axon initial segment of pyramidal cells, raises the possibility that this neuron, if GABAergic, may be responsible for some of the inhibitory processes (Somogyi et al., 1983).

The aims of the present study were: $(i)$ to establish whether axoaxonic cells, or their axons, similar to those in the monkey (Somogyi et al., 1983), are present in the hippocampus of the cat, a species used in electrophysiological studies; (ii) to map the distribution of GADcontaining neurons and their synaptic terminals in different regions of the cat hippocampus; and (iii) to establish whether the boutons of axoaxonic cells are GABAergic. To answer the first question we used Golgielectron microscopic examination of identified axons. To study the second and third questions we carried out a correlated light and electron microscopic examination of GAD-immunoreactive structures, wilh special attention to the axon initial segment. GAD-positive boutons have been shown to make synapses with axon initial segments (Ribak, 1978; Peters et al., 1982) in the cerebral cortex, and it has been suggested that chandelier cells (i.e., axoaxonic cells) are GABAergic in the cortex (Peters et al., 1982). However, neurons other than the specialized axoaxonic cells probably also make synapses with the initial segment; thus the origin of any individual GADpositive bouton is uncertain. However, if it can be demonstrated that all, or the large majority of, boutons in synaptic contact with the initial segment are GABAergic (i.e., contain GAD), the boutons of axoaxonic cells will also be included. Accordingly, in the present study, the proportion of boutons immunoreactive for GAD was established.

\section{Materials and Methods}

Antiserum. GAD was purified to homogeneity from mouse brain (Wu et al., 1973, 1982) and the antiserum (Code No. P4, 10/17) was raised in a rabbit. The rabbit was injected every second week with $30 \mu \mathrm{g}$ of purified GAD over a period of 10 weeks. The specificity and properties of the antiserum were established by immunodiffusion tests, immunoelectrophoresis, and microcomplement fixation (Saito et al., 1974; Wu et al., 1982).

Preparation of tissue sections. Two adult cats were used, one male and one female. The animals were sedated with ketamine hydrochloride (Ketanest, $0.4 \mathrm{ml} / \mathrm{kg}$, i.m.) and anesthetized with xylazine hydrochloride (Rompun, $1 \mathrm{ml} / \mathrm{kg}$ ). The right hippocampal formation was injected with colchicine (BDH Chemicals; $6 \mu \mathrm{g} / \mu \mathrm{l}$, dissolved in artificial cerebrospinal fluid) through glass micropipettes with a tip diameter of about $50 \mu \mathrm{m}$. Colchicine was used in order to increase the staining of GAD-containing cell bodies (Ribak et al., 1978). Two vertical penetrations were made $3 \mathrm{~mm}$ apart in the anterior-posterior direction, and $0.2 \mu \mathrm{l}$ of colchicine was injected, at each millimeter, while the capillary was withdrawn in 1-mm steps over a 5 -mm distance. Thus, altogether, $2 \mu \mathrm{l}$ of solution, containing $12 \mu \mathrm{g}$ of colchicine, were injected.

The animals were anesthetized again $24 \mathrm{hr}$ later with chloral hydrate $(350 \mathrm{mg} / \mathrm{kg}$, i.p.) and perfused through the heart, first with Tyrode's solution (gassed with $95 \%$ $\mathrm{O}_{2} / 5 \% \mathrm{CO}_{2}$ mixture) and then with a fixative containing $4 \%$ paraformaldehyde (TAAB Laboratories), $0.05 \%$ glutaraldehyde (TAAB), $0.2 \%$ picric acid dissolved in $0.1 \mathrm{M}$ phosphate buffer and prepared as described previously (Somogyi and Takagi, 1982). After perfusion the brain was removed from the skull and placed into the same fresh fixative for 1 to $2 \mathrm{hr}$ at $4^{\circ} \mathrm{C}$.

The hippocampus was sliced in a plane approximately parallel with the apical dendrites of pyramidal neurons. Small blocks from both the colchicine-injected hippocampus and the contralateral, left hippocampus were washed in several changes of $0.1 \mathrm{M}$ sodium phosphate buffer, $\mathrm{pH} 7.4$, followed by $10 \%$ and then $20 \%$ sucrose dissolved in the same buffer each time, until the blocks sank. The blocks were then frozen in liquid nitrogen and thawed in $0.1 \mathrm{M}$ phosphate buffer at room temperature. Eighty-micrometer thick sections were cut on a Vibratome (Oxford Instruments) and washed in $0.1 \mathrm{M}$ phosphate buffer.

Immunocytochemical procedure. Incubation of sec- 
tions was carried out in the following order at room temperature unless otherwise stated: $1 \mathrm{hr}$ in $20 \%$ normal goat serum (N. L. Cappel Laboratories); two $30-\mathrm{min}$ washes; $24 \mathrm{hr}$ at $4^{\circ} \mathrm{C}$ in the primary antiserum diluted to 1:500 or 1:1000; three 40-min washes; overnight in goat anti-rabbit IgG (Miles Laboratories) diluted to 1:40; three 40-min washes; 4 to $6 \mathrm{hr}$ in rabbit peroxidase-antiperoxidase (PAP) complex (Bioproducts Ltd.) diluted to 1:80; three 40 -min washes. For the first wash after each serum, phosphate-buffered saline (PBS) was used; thereafter, PBS containing $0.25 \%$ lambdal carrageenan (Sigma Chemical Co.) (Sofroniew and Schrell, 1982) was used. Only PBS was used after incubation in PAP. The primary antiserum and the PBS contained 1\% normal goat serum.

The sections were then preincubated for $20 \mathrm{~min}$ in 0.05\% 3,3'-diaminobenzidine tetrahydrochloride (Sigma) dissolved in $0.05 \mathrm{~m}$ Tris-HC1 buffer, $\mathrm{pH} 7.4$, followed by a reaction for $6 \mathrm{~min}$ in the same solution containing $0.01 \%$ hydrogen peroxide. After washing in the Tris buffer, the sections were postfixed for $1 \mathrm{hr}$ in $1 \% \mathrm{OsO}_{4}$ in $0.1 \mathrm{M}$ phosphate buffer ( $\mathrm{pH} 7.4$ ), and then dehydrated.

To enhance contrast for electron microscopy, the sections were stained with $1 \%$ uranyl acetate at the $70 \%$ alcohol dehydration state. No lead staining was used. For correlated light and electron microscopic study, sections were flat-embedded on slides in Durcupan ACM (Fluka) resin according to the method described earlier for immunostained sections (Somogyi and Takagi, 1982).

The flat-embedded sections were studied in the light microscope. Selected immunoreactive structures were photographed prior to re-embedding for electron microscopy. Serial ultrathin sections were mounted on Formvar-coated, single slot $(2 \times 1 \mathrm{~mm})$ grids. Electron micrographs were taken at $60 \mathrm{kV}$ on Philips 400 and JFOI. $100 \mathrm{~B}$ electron microscopes, using a 20 - or $30-\mu \mathrm{m}$ objective aperture.

To check for endogenous peroxidase activity, control sections were incubated in normal rabbit serum (diluted 1:500) in place of the anti-GAD serum. No immunoreactivity of nerve terminals was seen in the control sections, but peroxidase reaction endproduct was present over red blood cells, over large granules of cells associated with blood vessels, and in small granules in the cell bodies of some pyramidal neurons and glial cells. No reaction endproduct was found in sections incubated in the absence of $\mathrm{H}_{2} \mathrm{O}_{2}$.

Processing of Golgi material. Some tissue blocks (1 to $2 \mu \mathrm{m}$ thick) from the left hippocampus were left for 1 month in the same fixative as that used for perfusions; then they were washed free of fixative in $0.1 \mathrm{M}$ phosphate buffer. The blocks were immersed in $3.5 \%$ potassium dichromate solution containing $1 \% \mathrm{OsO}_{4}$ for 1 day and then were left in $0.65 \% \mathrm{AgNO}_{3}$ overnight. Sections $(80$ $\mu \mathrm{m}$ thick) were cut using a tissue chopper (Sorvall TC2 ), placed on slides in $100 \%$ glycerol, and studied in the light microscope. Selected areas were then gold toned (Fairén et al., 1977) after illumination as described previously (Somogyi et al., 1981). Dehydration, embedding, and processing for electron microscopy were the same as for the immunocytochemical material. Ultrathin sections were stained with lead citrate (Reynolds, 1963) and studied at $80 \mathrm{kV}$. The picric acid fixative employed in this study does not provide an ideal fine structural preserva- tion, but in our hands material fixed this way provides the largest variety of Golgi-impregnated interneurons and the most extensive impregnation of axons in Golgi material. Both in the monkey (Somogyi et al., 1983) and in the cat the use of this fixative made it much easier to obtain impregnated axoaxonic cells or their axons.

\section{Results}

\section{Characteristics of Golgi-impregnated axon initial segments of pyramidal cells}

The initial segment of the axon, leaving the cell at the base of the pyramidal neuron or from a main basal dendrite, is easily differentiated from the dendrites. Both the basal and apical dendrites are smooth along their proximal parts and acquire spines only about 50 to 100 $\mu \mathrm{m}$ away from the perikaryon. In contrast, the axon, which is usually thinner and tapers gradually away from the soma, exhibits spines, protrusions, and appendages starting at a distance of about $10 \mu \mathrm{m}$ from the perikaryon and continuing for about 40 to $60 \mu \mathrm{m}$ (Fig. 1). Beyond this region the axon becomes smooth and, if impregnated, can be traced through stratum oriens where it emits thin collaterals. These characteristics apply to most pyramidal cells seen in our material in the CAI (Fig. 1, $A$ and $B$ ), $\mathrm{CA} 2$, and $\mathrm{CA} 3$ regions (Fig. $1 C$ ) and are similar to those described by Amaral (1978) and Kosaka (1980) for the rat hippocampus. Rarely, in gold-toned material, thin axons parallel to the axon initial segment were found climbing along it and in contact with the initial segment through vasicosities (Fig. $1 A$ ). These varicose axons represent the specialized portions of a new type of local axon in the hippocampus and are described below. Because they exclusively contact axons of pyramidal cells, they are, by definition, the axons of axoaxonic cells.

\section{Light and electron microscopy of the axons of axoaxonic cells}

As in the hippocampus of the monkey (Somogyi et al., 1983), a characteristic Golgi-impregnated axon was encountered in all regions of the hippocampal formation of the cat where pyramidal cells occur. Because a detailed study was carried out in the monkey on similar cells, only a limited examination has been carried out here to confirm the specificity of these axons. The most conspicuous feature of this axon is its specialized, terminal segments consisting of 3 to 15 beads orientated parallel with the presumed course of pyramidal axon initial segments (Figs. 2 and $3 A$ ). The latter have a more regular course, perpendicular to the layers of the hippocampus, in the CA1 and CA2 regions and in the subiculum; thus it is easier to recognize the specialized terminal segments of axoaxonic cells in these areas (Figs. 2, $A$ and $B$, and $3 A$ ). In the CA3 region the axon initial segments of pyramidal neurons bend at various angles to the axis of apical dendrites; likewise, the terminal bouton rows of axoaxonic cells were also more irregular (Fig. 2, $C$ and $D$ ). The specialized terminal segments are 20 to $40 \mu \mathrm{m}$ long and they are interconnected by thin horizontal or arcadic collaterals. One terminal segment may consist of one or two rows of varicosities (Figs. 2 and $3 A$ ). The thin collaterals were seen to originate from main axons in the upper one-third of stratum pyramidale (Fig. 2), but in 

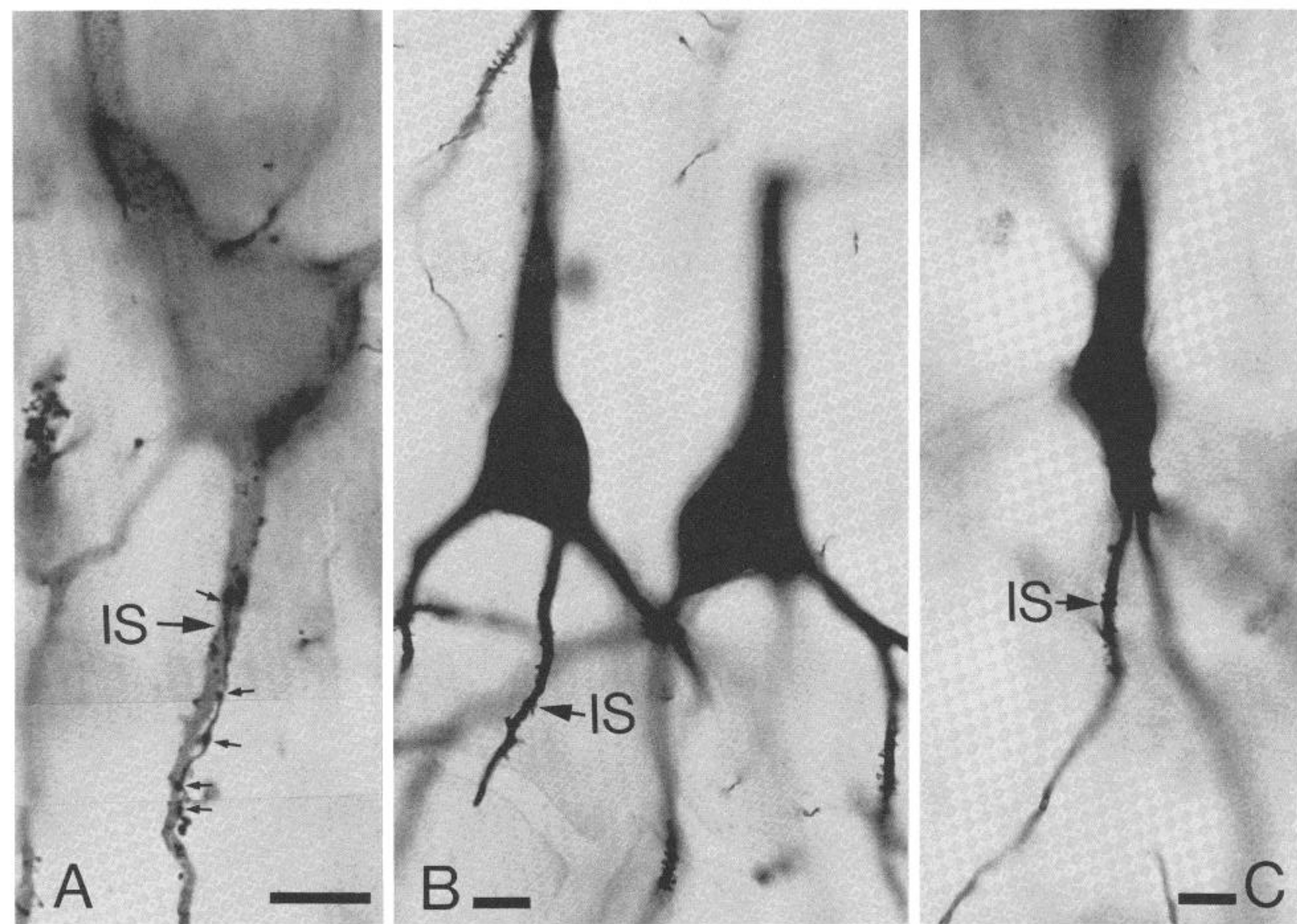

Figure 1. A, Golgi-stained, gold-toned pyramidal neuron in the CA1 region. The axon initial segment (IS) is followed and contacted by several varicosities (small arrows) of a thin fiber that originated from an axonal plexus forming specialized vertical segments. $B$ and $C$, Golgi-stained pyramidal neurons in the CA1 $(B)$ and CA3 $(C)$ regions. Note the numerous spines and protrusions on the axon initial segments. Scales, $10 \mu \mathrm{m}$.

the cat we have been unable to trace them back to their parent cell bodies. The largest axon arborizations of this type were found in the subiculum.

To ascertain that the specialized terminal axon segments situated at the base of pyramidal cells do in fact contact the initial segments of the axons, we studied six identified, gold-toned segments of two axon arborizations in the CA1 region (Fig. 3). All of the impregnated boutons, where the synaptic contact could be identified, were in contact with axon initial segments (Fig. $3, B, D$, and $E$ ), four of which were traced back to pyramidal cell perikarya. The axon initial segments could be identified by the presence of membrane undercoating (Fig. 3, B, D, and $E$ ) and microtubule fascicles. Although we had to compromise with regard to fine structural preservation in order to obtain the impregnated axons, the detail was sufficient to permit characterization of the synapses and postsynaptic element. The synaptic contacts formed by gold-toned boutons were symmetrical, or Gray's type II, with a small amount of postsynaptic dense material (Fig. $3, D$ and $E$ ). The impregnated terminal segments climbed along the initial segments and formed multiple contacts (Fig. $3 B$ ). The same axon initial segments received a large number of synaptic contacts from non-impregnated boutons, all of them forming symmetrical synapses (Fig. $3, B$ and $C$ ).
In order to determine what proportion of the total boutons in contact with the axon initial segment of an individual hippocampal pyramidal cell are derived from a single axoaxonic cell, we have re-examined the axoaxonic cells whose somas were impregnated in a previous study on the monkey (Somogyi et al., 1983). The results, shown in Table I, reveal that for three pyramidal cells about $37 \%$ of all the boutons on their axon initial segments came from a single axoaxonic cell. Preliminary studies on the Golgi-impregnated terminal bouton rows in the present cat material give a similar order of magnitude, but in the cat we cannot be sure of the origin of the terminals because they were not traced back to an impregnated interneuron.

\section{Specificity of the immunoperoxidase reaction}

In sections incubated with the anti-GAD serum, reaction endproduct was observed in axons, nerve terminals, and neuronal perikarya and their proximal dendrites. In perikarya the reaction endproduct was distributed either homogeneously in the cytoplasm, leaving the nucleus free (Fig. 4), or as small granules. These granules were observed in the pyramidal cells, where they were at the limit of the resolution of the light microscope. They were also present in control sections; therefore, it is concluded that they represent endogenous peroxidase activity. At 

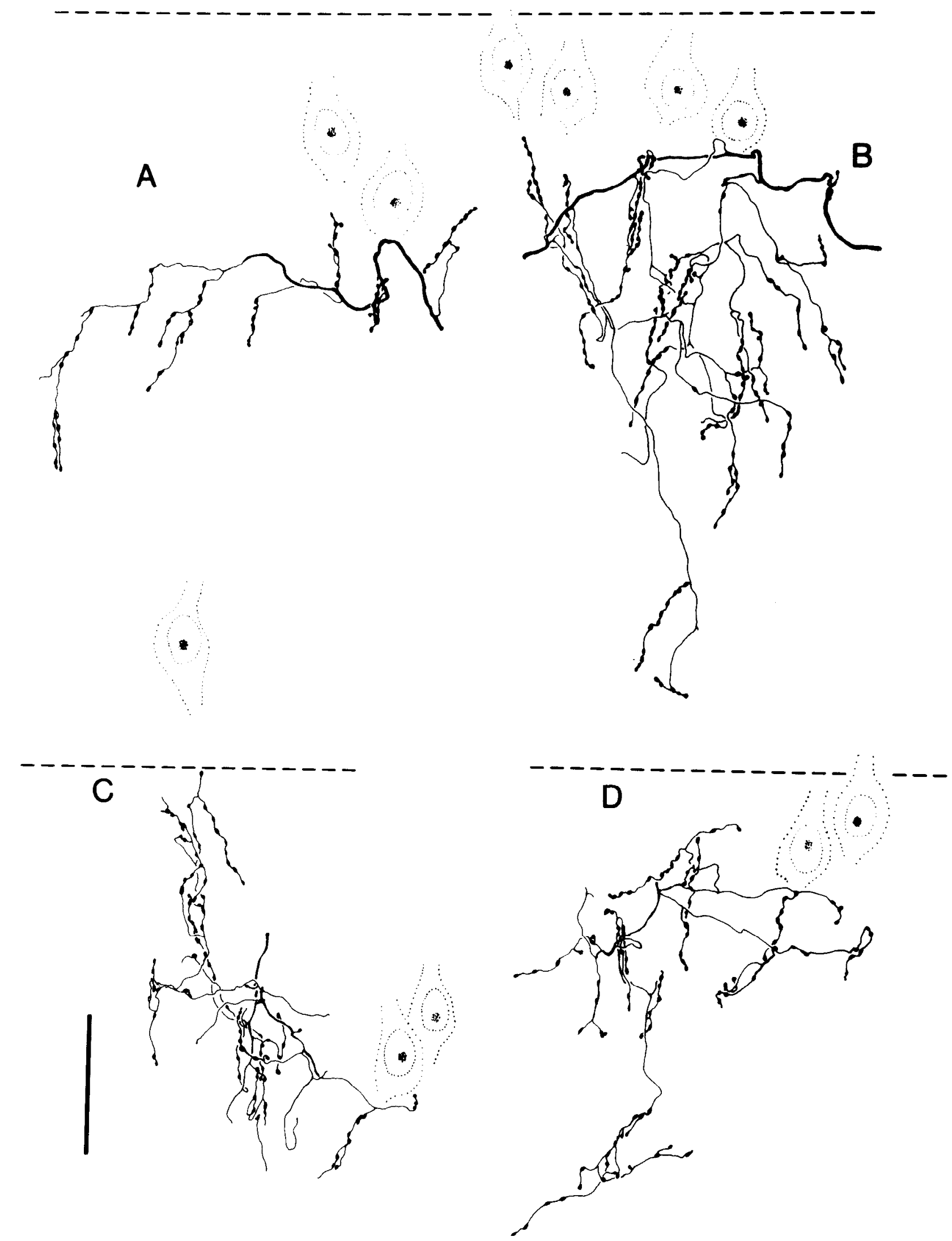

Figure 2. Camera lucida drawings of Golgi-impregnated axons with specialized terminal segments in the CA1 $(A$ and $B)$ and CA3 ( $C$ and $D$ ) regions. Dashed lines indicate the top of stratum pyramidale. The positions of some of the pyramidal cells that could be seen in the sections are shown as dotted outlines; note that the vertical segments of axons are situated at the base of the cells. The axon in $A$ was studied in the electron microscope and is shown in Figure 3. Scale, $50 \mu \mathrm{m}$. 

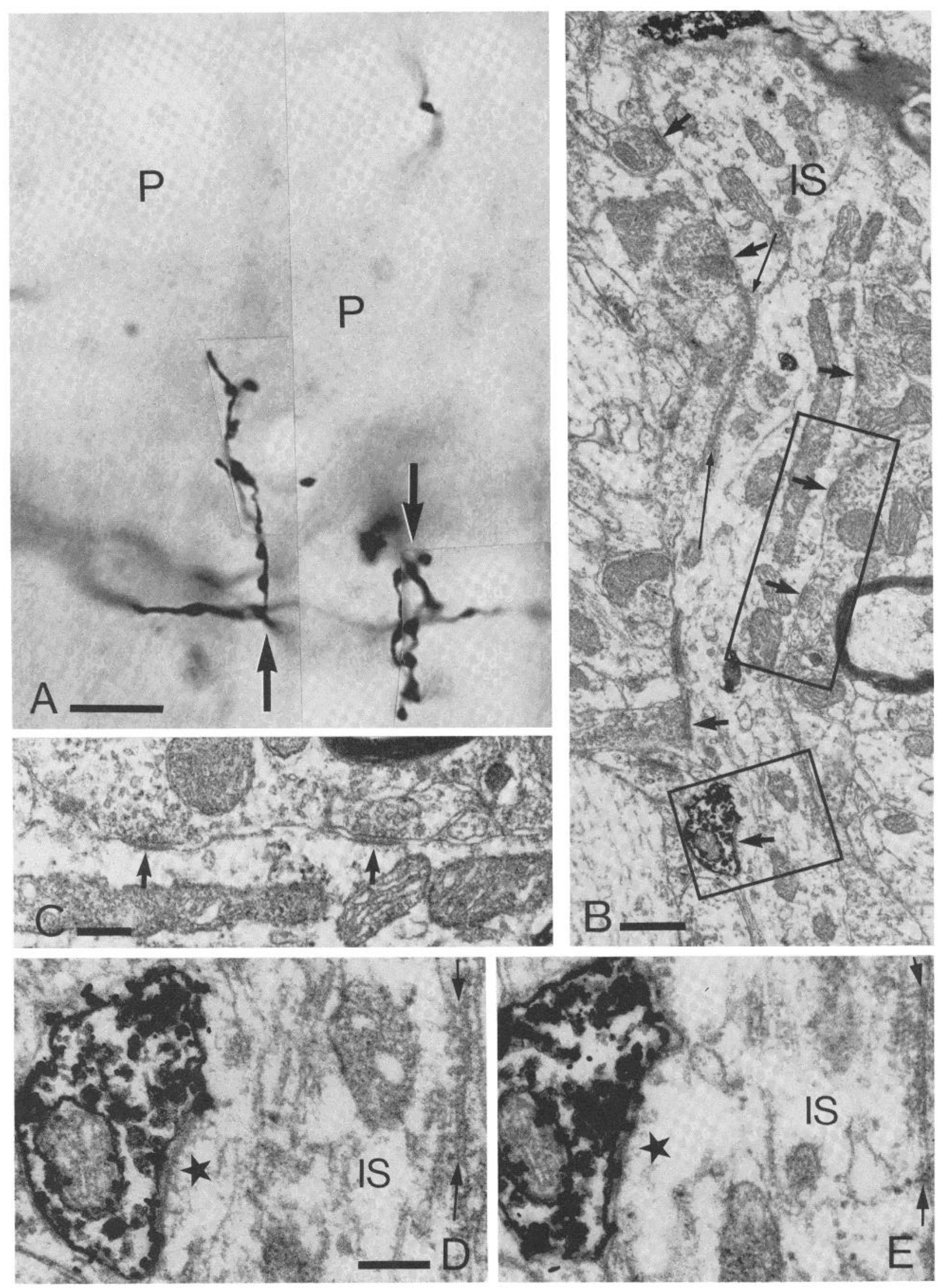

Figure 3. A, Light micrograph of a Golgi-stained and gold-toned axon which has specialized vertical axon segments (arrows); this is the axon shown in the drawing in figure $2 A$. Both segments are situated at the base of CA1 pyramidal cells $(P)$. $B$ to $E$, Electron micrographs. B, Axon initial segment (IS) of a pyramidal cell receiving numerous synaptic contacts (short arrows) from non-impregnated boutons and a Golgi-impregnated bouton (lower framed area) originating from a specialized axon segment which followed the initial segment. Long arrows mark membrane undercoating. $C$, Synaptic contacts (arrows) in the upper framed area in $B$ are shown at higher magnification. $D$ and $E$, Serial sections showing the synaptic contact (star) between a Golgi-impregnated axoaxonic bouton (lowerframed area in B) and the axon initial segment (IS). Arrows indicate a length of membrane with the characteristic undercoating of the initial segment. Scales: $A, 10 \mu \mathrm{m} ; B, 0.5 \mu \mathrm{m} ; C$ to $E$ : $0.2 \mu \mathrm{m}$. 
TABLE I

Numbers of boutons in contact with the axon initial segments of three pyramidal neurons in the CAl area of the monkey hippocampus that come from the axon collaterals of a single Golgiimpregnated axoaxonic cell ${ }^{a}$

\begin{tabular}{cccc}
\hline $\begin{array}{c}\text { Pyramidal } \\
\text { Cell No. }\end{array}$ & $\begin{array}{c}\text { No. of } \\
\text { Golgi- } \\
\text { impregnated } \\
\text { Boutons } \\
\text { on AIS }\end{array}$ & $\begin{array}{c}\text { Total No. of } \\
\text { Boutons } \\
\text { on AIS }\end{array}$ & $\begin{array}{c}\text { \% of 'l'otal from One } \\
\text { Axoaxonic Cell }\end{array}$ \\
\hline 1 & 30 & 78 & 38.5 \\
2 & 19 & 50 & 38.0 \\
3 & 14 & 40 & 35.0 \\
\hline
\end{tabular}

${ }^{a}$ The cell body of the axoaxonic cell was in the pyramidal cell layer; a similar neuron is illustrated in a previous publication (Somogyi et al., 1983) which also contains electron micrographs of some of the Golgiimpregnated, gold-toned boutons. Serial ultrathin sections were taken through several axon initial segments (AIS) which received input from the axoaxonic cell; three were selected because all, or nearly all, of the initial segment could be recovered for study and because the initial segment could be traced back to a pyramidal cell. The total number of boutons and the numbers of gold-toned boutons were counted on the initial segments of the three pyramidal neurons: cell 1 had more than two terminal bouton rows from the same interneuron along its initial segment, cell 2 had two rows, and cell 3 had one terminal bouton row.

the electron microscopic level these granules correspond to small vacuoles containing reaction endproduct and having an electron translucent matrix (Fig. 10) with occasional membrane-limited vesicles.

\section{Distribution of $G A D$-immunoreactive neuronal perikarya in the $C A 1$ to $C A 3$ regions}

The pyramidal cells of stratum pyramidale did not show GAD immunoreactivity. There were pyramidally shaped neurons among the immunoreactive neurons in stratum oriens and the alveus (Fig. 4, $A$ and $B$ ), but these are varieties of large multipolar neurons as seen in our Golgi material, and they have smooth or sparsely spiny dendrites in contrast to pyramidal cells of stratum pyramidale, which have densely spinous dendrites.

All of the layers from the alveus to stratum moleculare contain GAD-posilive perikarya. The largest, triangular or multipolar neurons were found in the alveus and in the lower half of stratum oriens and measured 20 to 30 $\mu \mathrm{m}$ for the short axis and up to $50 \mu \mathrm{m}$ for the long axis. Medium-size (20 to $30 \mu \mathrm{m})$, multipolar perikarya were the most common and were present in all layers. Medium-size fusiform, spindle-shaped neurons with their long axis perpendicular to the layers were found in strata oriens, pyramidale, and radiatum (Fig. $4, A$ and $B$ ). The most characteristic GAD-positive neuron found in the stratum pyramidale was a small ovoid or fusiform cell measuring 8 to $15 \mu \mathrm{m}$ for the short axis and 12 to $20 \mu \mathrm{m}$ for the long axis. This neuron has mainly been seen in the pyramidal layer (Fig. 4, $A$ to $E$ ) and has also been found in the subiculum (Fig. $4 F$ ).

The description above is based mainly on the colchicine-injected material, but immunoreactive perikarya were also found in normal material. The large neurons in the alveus and the small neurons of stratum pyramidale exhibit the strongest immunoreactivity and are often seen without colchicine treatment (Fig. $4, D$ to $F$ ).

\section{Distribution of GAD-immunoreactive boutons and fibers}

On the basis of light microscopic examination alone, it is not possible to establish whether an immunoreactive varicosity is a synaptic bouton. However, since subsequent electron microscopic examination of light microscopically identified GAD-positive varicosities has shown that the great majority of them are in fact boutons, we will use this latter term in the description. GAD-immunoreactive fibers and boutons were found in all layers. The most conspicuous patterns they form are the pericellular nets they establish around pyramidal cells (Figs. 5 and $7 A$ ). The other layers also contain a very large number of immunoreactive puncta and fiber segments, but there the boutons are not distributed in any pattern which would suggest the postsynaptic element (Fig. $5 E$ ). The only exception is perhaps the lower half of stratum radiatum where the thick apical dendrites can be recognized as they are outlined by immunoreactive boutons (Fig. $5 C$ ).

In the pyramidal cell layer of the CA1 to CA3 regions and in the subiculum, most pyramidal neurons are outlined by immunoreactive boutons (Fig. 5). When the surface of the soma is reconstructed from photographs taken at different focal planes, the large number of boutons can readily be appreciated (Fig. 5B). Both apical and basal dendrites were followed by varicose fibers (Fig. $5, A$ and $C$ ). Upon closer examination, a less conspicuous but very characteristic tube-like arrangement of immunoreactive varicosities with a diameter of 2 to $4 \mu \mathrm{m}$ could also be seen (Figs. $5, D$ and $E$, and $7 A$ ). Such structures appeared to contain the highest concentration of immunoreactive boutons. Sometimes the GAD-positive cylinders could be traced back to the base of pyramidal cells, suggesting that they were axon initial segments, but as the varicosities became scarce toward the soma (Figs. 5, $D$ and $E$, and $7 A$ ), this could not be established with light microscopy.

\section{Synaptic connections of GAD-immunoreactive nerve terminals}

Immunocytochemical staining for GAD in the hippocampus reveals mainly the perikarya and terminals of neurons and shows very little of the dendritic arborization or the non-terminal axons. As a result it is not possible to establish with this method alone what morphological type of neurons the stained perikarya represent or which terminals belong to a given class of perikarya. Therefore, we have only examined the postsynaptic targets and the type of synapses of GAD-positive terminals here.

The use of identified structures for correlated light and electron microscopy. The primary aim of this study was to examine the distribution of GAD-positive terminals on different parts of pyramidal cells. In random electron microscopic sections, however, it is not always possible to determine whether a dendrite belongs in fact to a pyramidal cell, and it is not easy to find small structures like axon initial segments. Therefore, the electron microscopic study was carried out in the CA1 region, in areas studied and photographed first at the light 

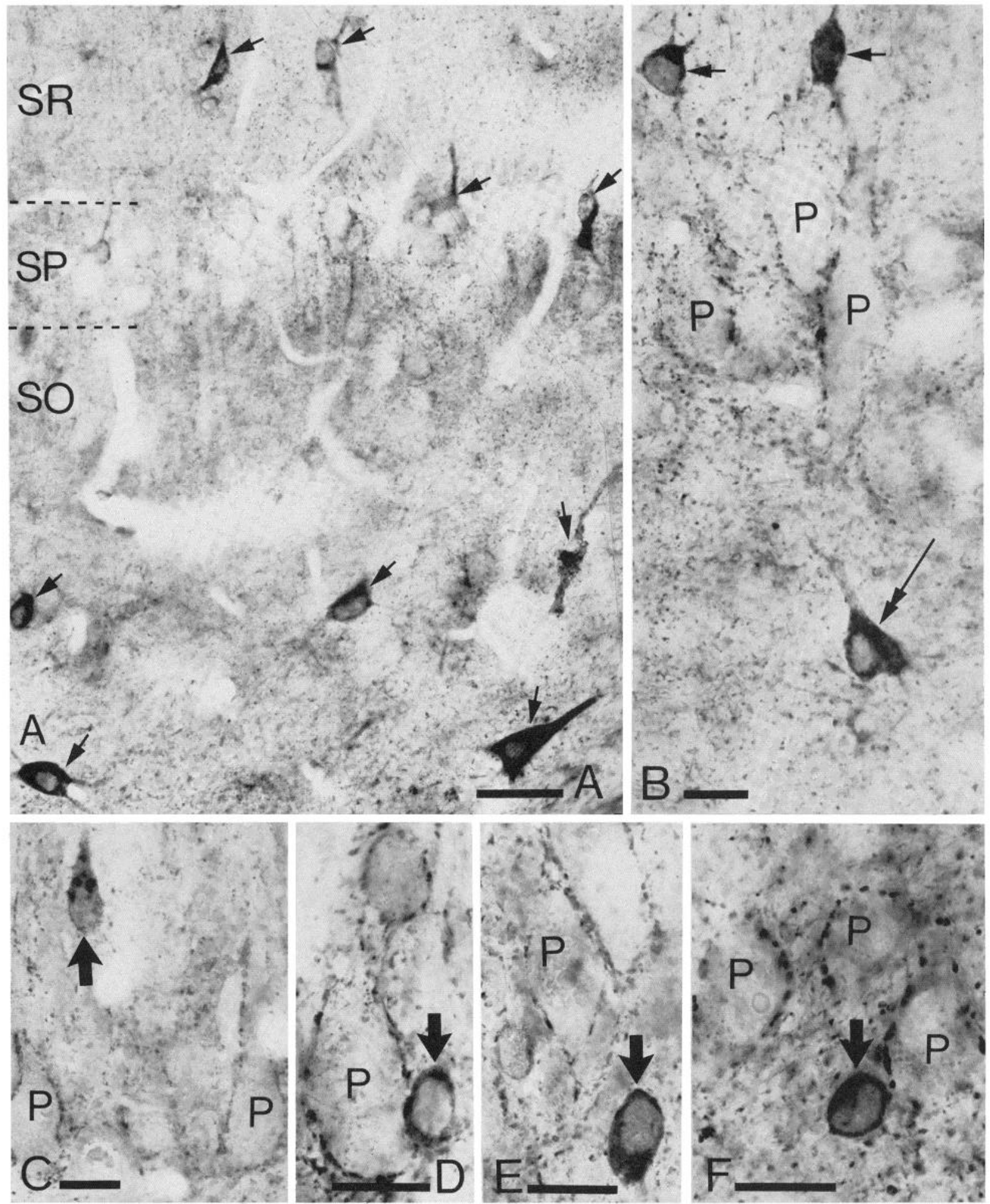

Figure 4. Light micrographs of GAD-immunoreactive neurons in different regions of the hippocampus. The sections (70 $\mu \mathrm{m}$ thick) had been fixed in osmium tetroxide and were used subsequently for electron microscopy. A, The neurons (arrows) in the alveus $(A)$, stratum oriens $(S O)$, stratum pyramidale $(S P)$, and stratum radiatum $(S R)$ have different sizes and shapes in the CA1 region. $B$, Small fusiform and multipolar GAD-positive cells (arrows) in the stratum pyramidale and a larger pyramidally shaped cell (double-headed arrow) in the stratum oriens of the CA3 region. $C$ to $F$, Small, usually fusiform or ovoid GADpositive neurons (large arrows) characteristic of the pyramidal cell layer in the CA3 $(C$ and $D)$ and CA2 $(E)$ regions and in the subiculum $(F)$. Pyramidal neurons $(P)$ are surrounded by immunoreactive fibers and varicosities. $A, B$, and $C$ are from a colchicine-treated hippocampus. Scales: $A, 50 \mu \mathrm{m} ; B$ to $F, 20 \mu \mathrm{m}$. 

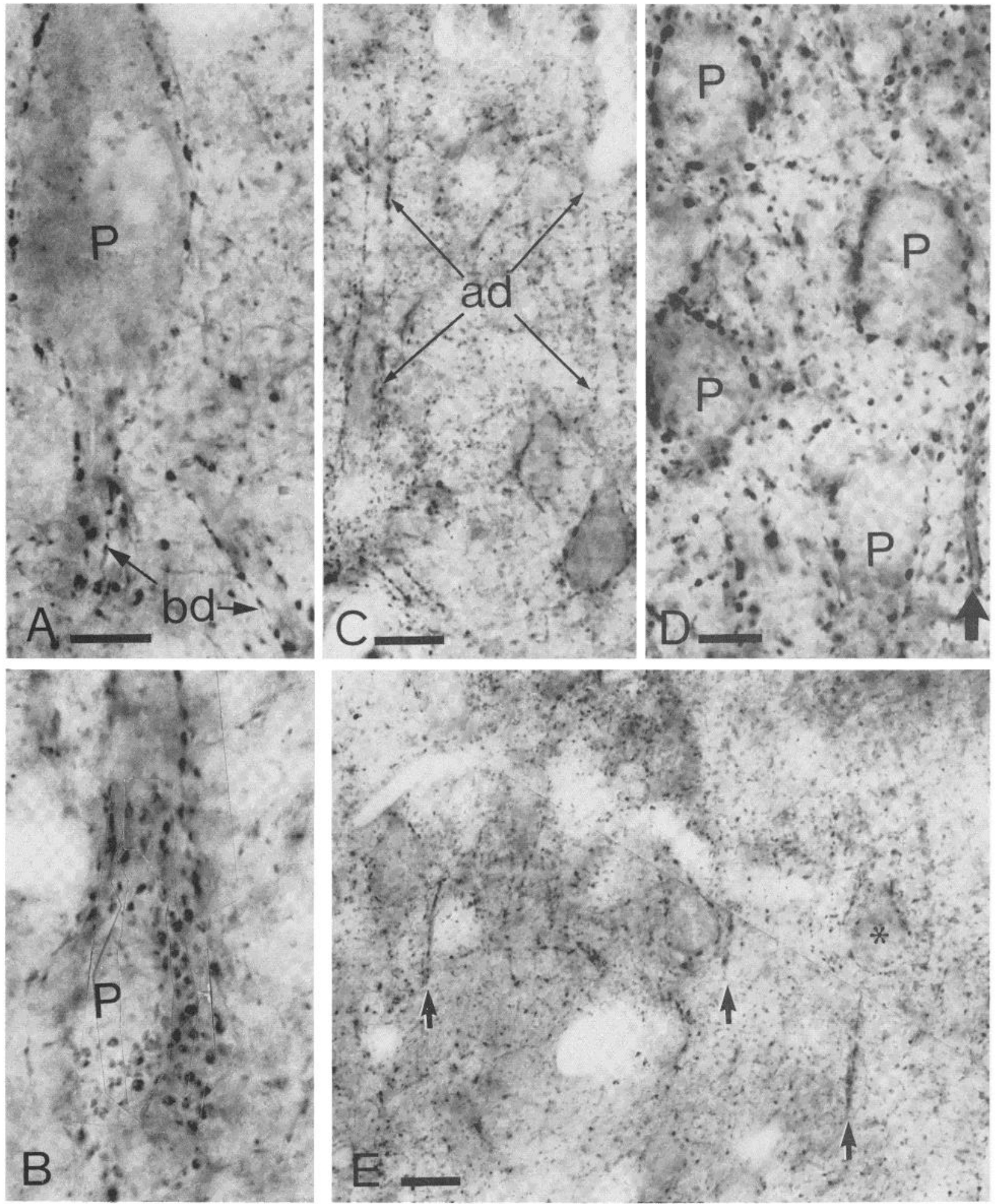

Figure 5. Light micrographs taken to show GAD-immunoreactive varicosities distributed on different parts of pyramidal neurons $(P)$ in the CA1 $(C$ and $E)$ and CA2 $(A$ and $B)$ regions and in the subiculum $(D)$. The perikarya, basal dendrites $(b d)$, apical dendrites $(a d)$, and axon initial segments (thick arrow in $D$; arrows in $E$ ) of many pyramidal cells are surrounded by immunoreactive punctate structures. The large pyramidal neuron photographed in cross-section in $A$ is shown at the same magnification in a montage in $B$ with its surface reconstructed from photographs taken at several different focal planes to illustrate the large number of immunoreactive varicosities converging onto the perikaryon. The asterisk in $E$ marks a pyramidal neuron shown at higher magnification in Figure $7 A$ (labeled $P_{1}$ ) and at the electron microscopic level in Figures 6 and 7 . Scales: $A, B$, and $D, 10 \mu \mathrm{m} ; C$ and $E, 20 \mu \mathrm{m}$. 
microscopic level. The use of this procedure of direct correlation has already provided valuable information in previous immunocytochemical studies (Somogyi et al., 1982a, b; Takagi et al., 1983; Bolam et al., 1983). In the present study the correlated approach was especially useful for the study of axon initial segments (Figs. 6 and 7).

Localization of immunoperoxidase reaction endproduct in nerve terminals. The unlabeled antibody-peroxidase method is not suitable for the determination of the fine structural localization of GAD. Thus, the reaction endproduct was found on the surface of all intracellular structures such as synaptic vesicles, smooth endoplasmic reticulum, mitochondria, plasma membrane, and microtubules (Figs. 6 to 10). Occasionally, the dense matrix of large granulated vesicles within immunostained boutons also appeared to contain reaction endproduct (Fig. 10B).

Synaptic connections of GAD-immunoreactive boutons. The immunoreactive boutons were either en passant or boutons terminaux type. They all formed symmetrical membrane contacts irrespective of the postsynaptic element. The boutons contained small pleomorphic vesicles, rarely large granulated vesicles, and a relatively large number of mitochondria. Immunoreactive boutons were in synaptic contact with dendritic shafts, pyramidal and nonpyramidal cell perikarya, and axon initial segments of pyramidal cells.

Dendrites. As could be predicted from light microscopy (Fig. 5, $A$ and $C$ ), the main shafts of both apical (not illustrated) and basal dendrites (Fig. 9, $A$ and $B$ ) of pyramidal cells received GAD-positive terminals, but the density of contacts was lower than on the soma. In many cases, in specimens obtained from the surface of the incubated sections where the penetration of the antibodies was not restricted, all of the boutons forming symmetrical synaptic contacts on a given dendrite were GAD positive. Thin dendrites were also seen receiving occasional synapses from immunoreactive boutons (Figs. $8, C$ and $D$, and $10 B$ ). Some of them receive few synapses and, as they were found in continuity with the main dendrites, they represent the secondary and tertiary spiny dendrites of pyramidal cells (Figs. 8, $C$ and $D$, and $10 B$ ). Other thin dendrites are also richly covered by non-immunoreactive synaptic terminals, many of them the asymmetrical type. These dendrites probably belong to nonpyramidal neurons.

Pyramidal cell perikarya. All synaptic contacts are symmetrical or Gray type II on the soma of pyramidal cells, and in the upper region of the incubated thick sections, most such boutons are immunoreactive. Several boutons may be interconnected by thin fibers; therefore, it seems that the same afferent fiber provides multiple GAD-positive synaptic contacts to a perikaryon. In spite of the impressive density of boutons seen in the light microscope (Figs. 5, $A$ and $B$, and $7 A$ ), in electron microscopic sections the boutons are scattered on the surface of the perikaryon, usually 3 to 10 forming synaptic contact in the plane of one section (Figs. $6 A$ and $10, A$ and $B$ ). There does not seem to be a preferential distribution of boutons on any part of the perikaryon. The axon hillock region has the same density of boutons as other parts of the soma.
Pyramidal cell axon initial segments. Besides their characteristic origin at the base of the pyramidal cells, axon initial segments can be recognized on the basis of unique fine structural features (Palay et al., 1968). This part of the neuron contains fasciculated microtubules (Figs. $6 B, 7 C$, and $8 A$ ), has a multilayered electron-dense membrane undercoating (Figs. $7 C$ and $8 A$ ), and contains numerous cisternal organelles (Figs. $6 B, 7 C$, and $8, A$ and $B)$. In addition, scattered ribosomes and a very large number of coated pits and vesicles associated with the axon membrane were also observed. Electron microscopic examination also revealed that the protrusions observed on the axon initial segment of Golgi-stained cells are in fact spines that often, but not always, contain a cisternal organelle (Figs. $8 A$ and $9 D$ ). The membrane of the spine also has the electron-dense undercoating (Fig. 8A).

Nineteen light microscopically identified axon initial segments were studied in order to count the proportion of GAD-immunoreactive synaptic nerve terminals. To reduce the proportion of false negative boutons, that is, those which contain GAD but are not stained because of the lack of penetration of antibodies, the axon initial segments were chosen from the upper $10 \mu \mathrm{m}$ of the thick sections. As can be seen from Table II, the great majority of boutons are immunoreactive. They are distributed unevenly along the initial segment. The first $10 \mu \mathrm{m}$ receive fewer synaptic contacts (Fig. $9 A$ ); they gradually become more numerous, covering the initial segment almost completely at 20 to $50 \mu \mathrm{m}$ from the perikaryon (Figs. 6 and $9, C$ and $D$ ). This region corresponds to the spine-rich zone seen in Golgi material (Fig. 1, $B$ and $C$ ) and to the tube-like GAD-positive structures observed at the light microscopic level. Of 208 synaptic nerve terminals, 92.3\% were GAD positive; the rest either did not contain GAD or were not penetrated by the antibodies. In many sections from the surface of the thick section, all, or nearly all, of the boutons in contact with the axon initial segment were GAD positive (Fig. 9, $C$ and $D$ ). As the serial sectioning proceeded deeper into the thick section, the proportion of GAD-positive boutons decreased gradually on the same initial segment. No attempt was made to count all the boutons along a single initial segment.

Both GAD-positive and non-immunoreactive boutons on the axon initial segment exhibit similar morphological features (Fig. $8 A$ ), and they do not seem to be different from those making synapses with other structures (Figs. 7, $B$ and $C, 8 C, 9, B$ to $D$, and 10 ). All of the synaptic contacts were symmetrical or Gray's type II, both on the initial segment proper and on its spines (Figs. $6 B, 7 C, 8$, and $9 C$ and $D$ ). The postsynaptic membrane specialization, an electron-dense layer of granulated material which starts at the inner electron-dense lamina of the axon membrane (Figs. $7 C$ and $8 A$ ), is easily differentiated from the membrane undercoating of the rest of the axon initial segment. The latter three-layered undercoating is interrupted at the synaptic junctions (Figs. $7 C$ and $8 A$ ) and its densest lamina is separated from the axon membrane by a thin electron-lucent zone (Figs. $7 C$ and $8, A$, and $C$ ).

Mast of the GAD-positive synaptic boutons along the 

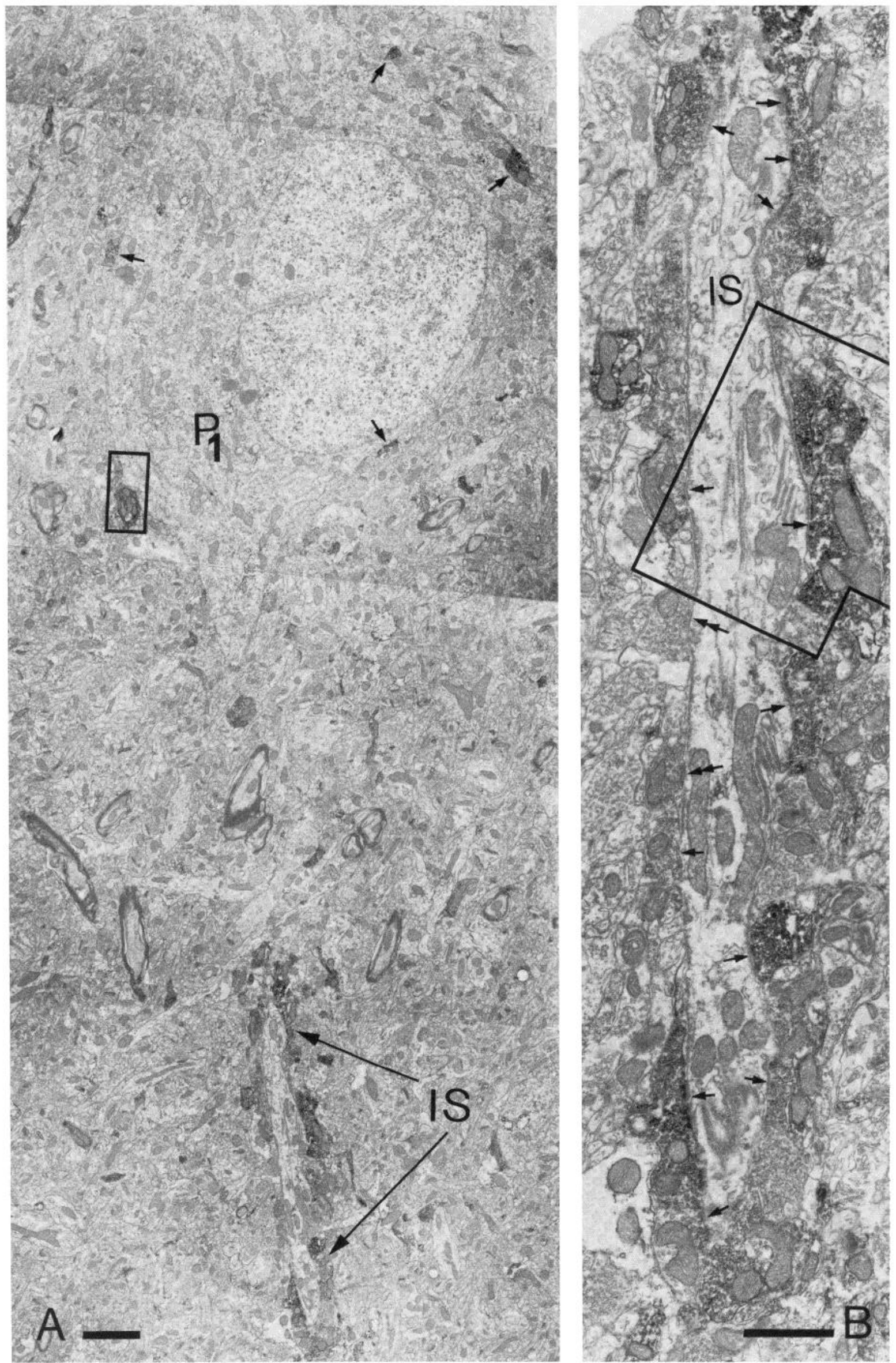

Figure 6. Electron micrographs of a pyramidal cell $\left(P_{1}\right)$ and its axon initial segment (IS) in the CA1 region; the same cell is shown in the light micrographs in Figures $5 E$ and $7 A$. $A$, The perikaryon receives several synapses (arrows) from immunoreactive boutons, but their density is much lower than on the initial segment. The framed area is shown in Figure $7 B$ at higher magnification. $B$, The initial segment is almost completely covered with both immunoreactive (arrows) and nonreactive (doubleheaded arrows) boutons. The framed area is shown in Figure $7 C$. Scales: $A, 2 \mu \mathrm{m} ; B, 1 \mu \mathrm{m}$. 

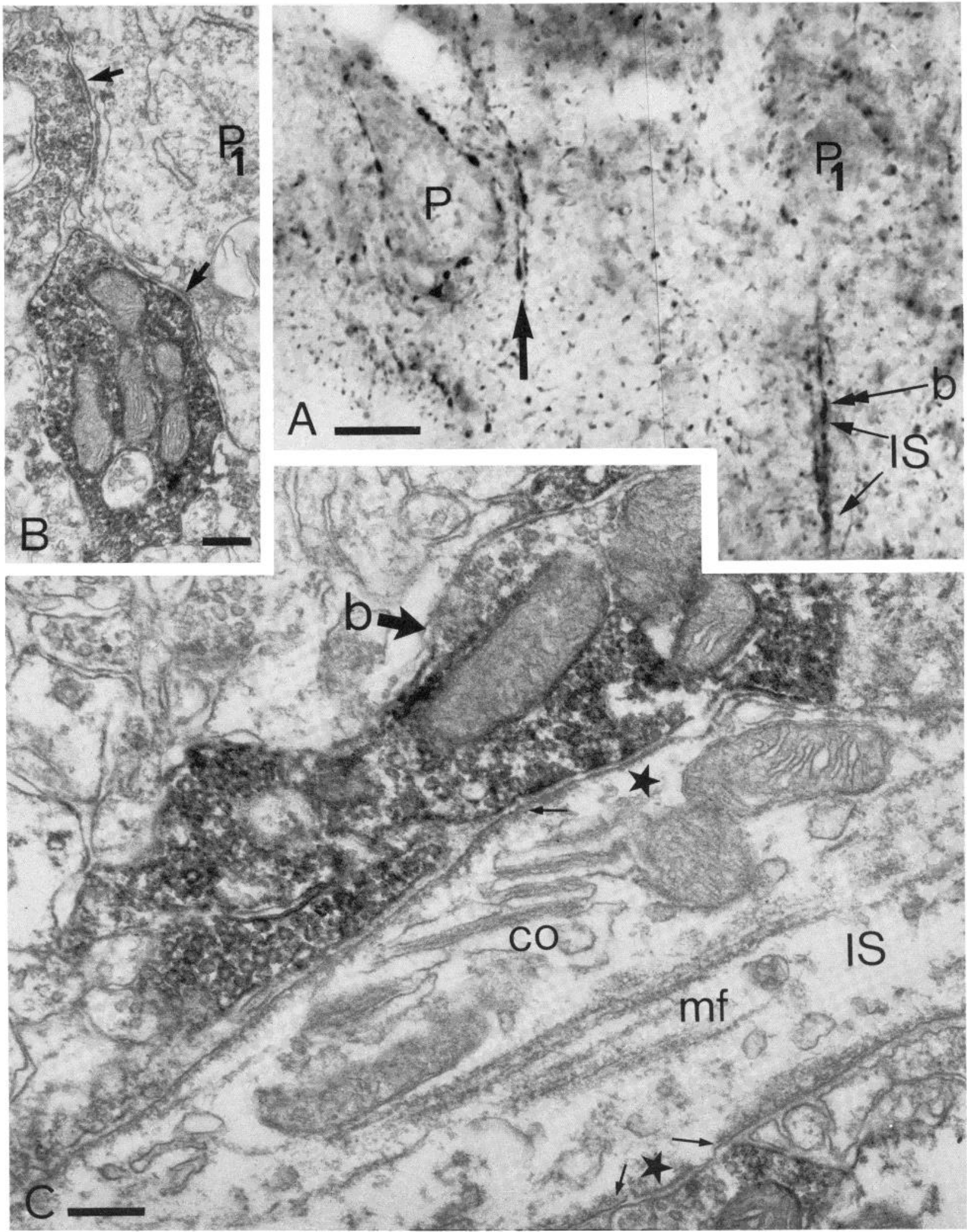

Figure 7. $A$, Light micrograph of an area in the CA1 region, also shown in Figure $5 E$, to illustrate pyramidal cells $\left(P, P_{1}\right)$ and axon initial segments (IS, large arrow) surrounded by immunoreactive varicosities. One large bouton $(b)$ can be identified in the electron micrographs in Figure 6 and it is also shown in a high power electron micrograph in $C$. B, Two immunoreactive boutons, shown in low power in Figure $6 A$, form symmetrical synaptic contacts (arrows) with the perikaryon of neuron $\mathrm{P}_{1}$. $C$, Two immunoreactive boutons, one of which $(b)$ is also shown in $A$ and in Figure 6, form symmetrical synaptic contacts (stars) with the axon initial segment $(I S)$ of pyramidal neuron $\mathrm{P}_{1}$. The IS contains a cisternal organelle $(c o)$ and microtuble fascicles $(m f)$ and has a characteristic membrane undercoating (small arrows) which is interrupted at the synaptic active zones. Scales: $A, 10 \mu \mathrm{m} ; B$ and $C, 0.2 \mu \mathrm{m}$. 

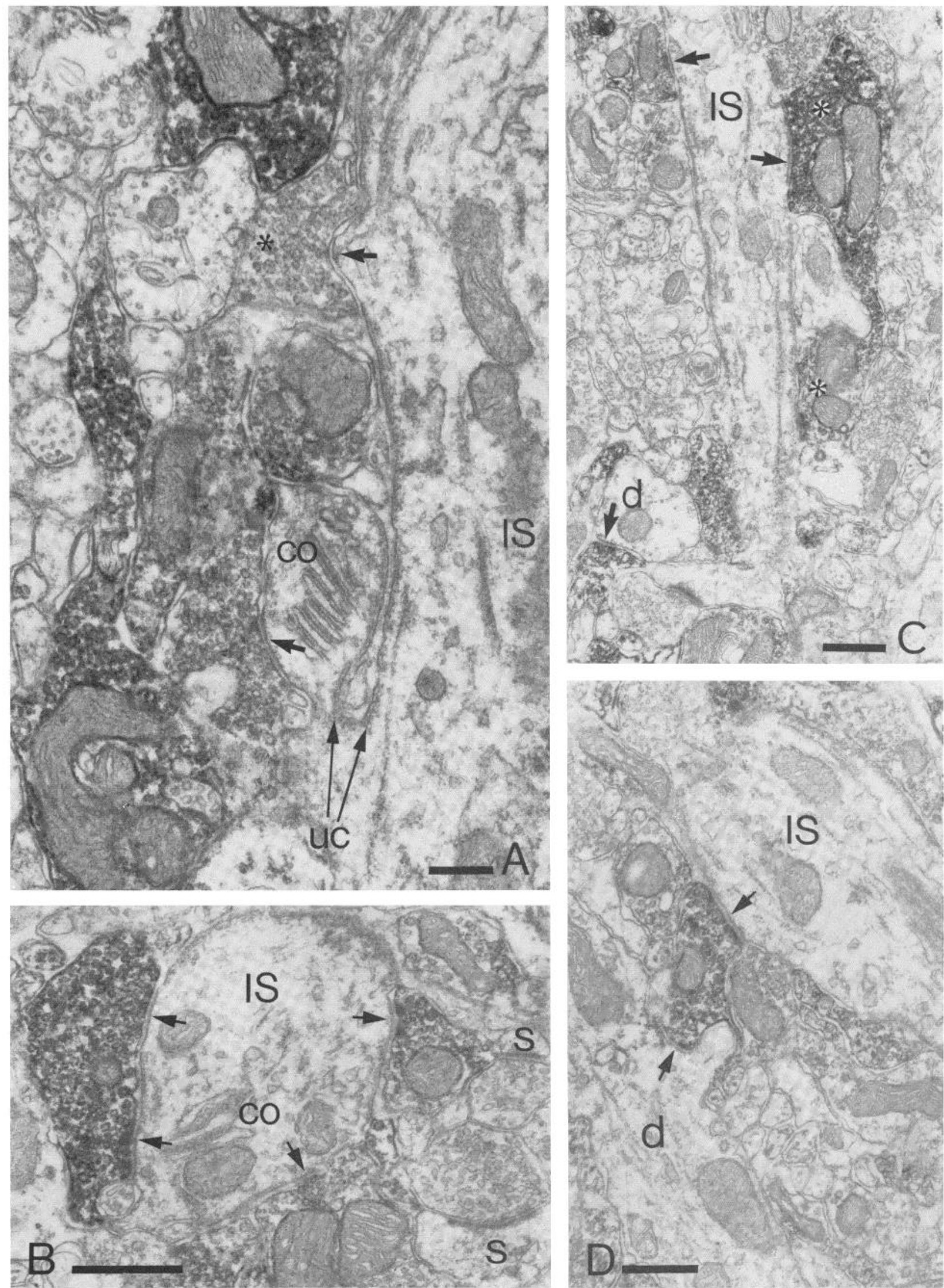

Figure 8. A, A typical spine containing a cisternal organelle (co) originates from a pyramidal cell axon initial segment (IS) and receives a symmetrical synapse (short arrows) from an immunoreactive bouton. The membrane of both the spine and the IS is underlined by an undercoating $(u c)$. A non-immunoreactive bouton (asterisk) forms a synaptic contact (short arrow) with the initial segment. $B$, Cross-section of an initial segment (IS) that receives symmetrical synaptic contacts from immunoreactive boutons (arrows), while neighboring spines $(s)$ receive asymmetrical synapses from non-immunoreactive boutons. $C$, An immunoreactive varicose fiber (asterisks) follows the initial segment (IS) which receives synapses from these and other boutons (arrows). A small dendrite $(d)$ in stratum oriens also receives a synapse (arrow) from an immunoreactive bouton. $D$, Rarely, immunoreactive boutons forming synapses (arrows) with both an initial segment (IS) and a dendrite $(d)$ were found. Scales: $A$, $0.2 \mu \mathrm{m} ; B$ to $D, 0.5 \mu \mathrm{m}$. 

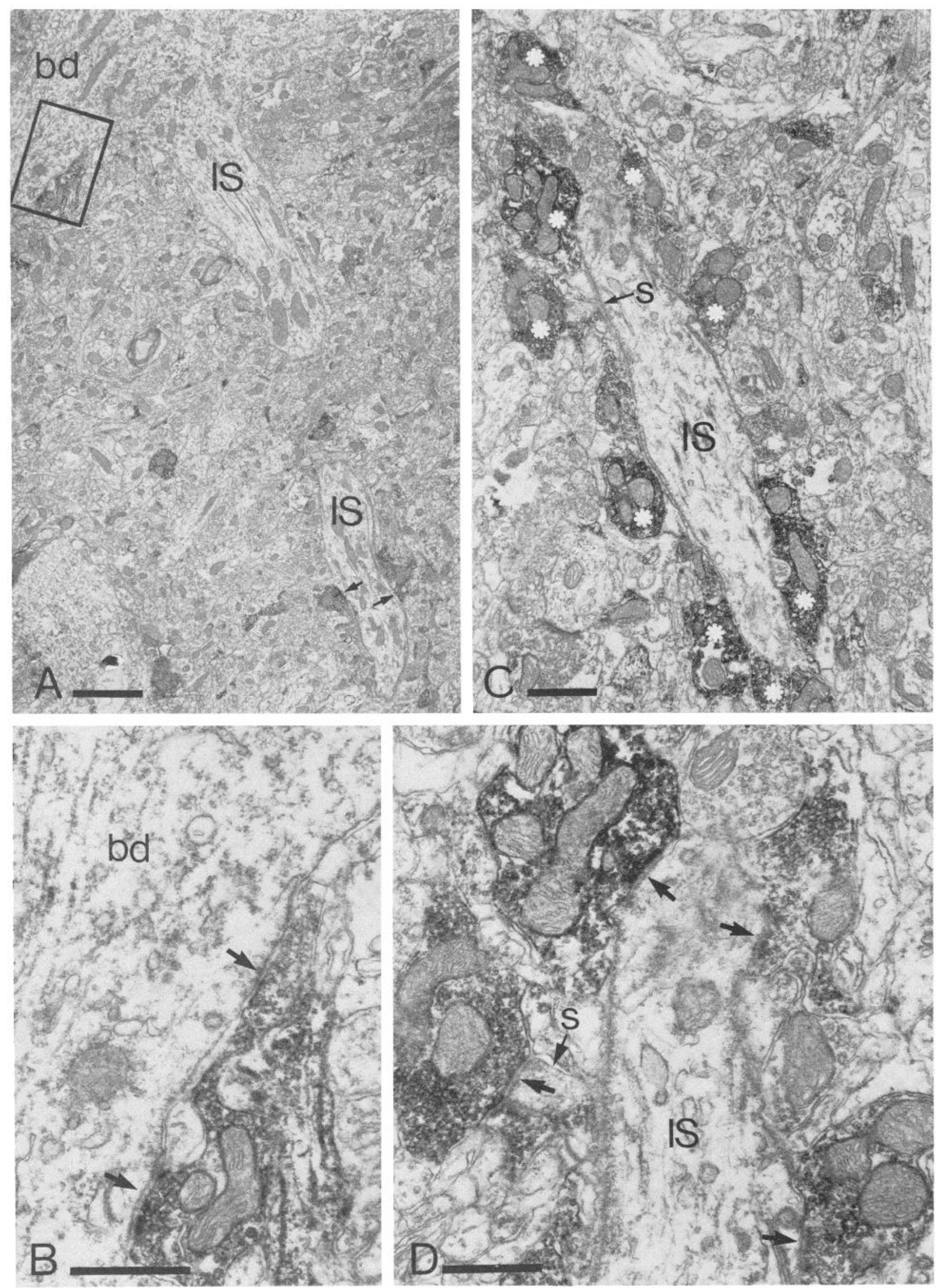

Figure 9. A, Initial segment (IS) originating from a basal dendrite $(b d)$. The framed area is reproduced at higher magnification in $B$ and shows GAD-immunoreactive boutons in synaptic contact with the dendrite. The proximal part of the initial segment receives few immunoreactive synapses (arrows). $C$, The distal initial segment, is surrounded by many immunoreactive synaptic boutons (white asterisks). D, Higher power micrograph of the same initial segment (IS) and its spine (s) showing symmetrical synaptic contacts (arrows) with GAD-positive boutons. Scales: $A, 2 \mu \mathrm{m} ; B$ and $D, 0.5 \mu \mathrm{m} ; C, 1 \mu \mathrm{m}$. 
TABLE II

Number of synaptic terminals on all of the 19 axon initial segments observed in the present study

Some of the axon initial segments were seen only in single electron microscopic sections, others with the higher number of synapses were followed in serial sections. None of the initial segments was completely reconstructed

\begin{tabular}{|c|c|c|}
\hline & $\begin{array}{c}\text { No. of } \\
\text { GAD-positive } \\
\text { Synaplic } \\
\text { Terminals }\end{array}$ & $\begin{array}{c}\text { No. of } \\
\text { Non-Immunoreactive } \\
\text { Synaptic } \\
\text { Terminals }\end{array}$ \\
\hline & 28 & 2 \\
\hline & 25 & 1 \\
\hline & 21 & 1 \\
\hline & 20 & 3 \\
\hline & 14 & 1 \\
\hline & 13 & 0 \\
\hline & 11 & 2 \\
\hline & 10 & 3 \\
\hline & 10 & 1 \\
\hline & 7 & 0 \\
\hline & 5 & 0 \\
\hline & 4 & 1 \\
\hline & 4 & 0 \\
\hline & 4 & 0 \\
\hline & 4 & 0 \\
\hline & 4 & 0 \\
\hline & 3 & 0 \\
\hline & 3 & 0 \\
\hline & 2 & 1 \\
\hline Total & $192(92.3 \%)$ & $16(7.7 \%)$ \\
\hline
\end{tabular}

axon initial segment establish synapses only with the axon initial segment. Only two were found in the present study to make synapses both with an initial segment and with a dendrite (Fig. $8 D$ ). In longitudinal sections, many of the boutons were seen to originate from thin fibers climbing along the initial segment (Fig. $8 \mathrm{C}$ ). Thus, they were similar to the specialized terminal portions of axoaxonic cells.

\section{Discussion}

We have found that there is a specialized type of axon in the cat hippocampus of the same kind as that described previously in the monkey hippocampus (Somogyi et al., 1983). All of the identified Golgi-impregnated boutons of these axons in the cat were in synaptic contact exclusively with axon initial segments, and one of the specialized terminal axon segments made multiple synaptic contacts on the same axon initial segment. This arrangement is identical to that found on the axon initial segment of pyramidal cells in the neocortex (Somogyi, 1977, 1979; Somogyi et al., 1979, 1982a; Fairén and Valverde, 1980; Peters et al., 1982) and provides an explanation for the large number of synaptic boutons on the initial segments of hippocampal pyramidal neurons (Andersen, 1976; Kosaka, 1980). Unfortunately the parent cell bodies of the axons were not impregnated in the cat hippocampus, a feature frequently observed in Golgi studies on this type of neuron (Somogyi, 1977; Fairén and Valverde, 1980; Peters et al., 1982; Somogyi et al., 1982a); but in the monkey hippocampus it has been demonstrated that the terminal axon segments originate from local interneurons (Somogyi et al., 1983). We therefore suggest that the terminal bouton rows in the cat hippocampus are derived from interneurons, although it cannot yet be excluded that they might originate from neurons outside the hippocampus.

The neurons in the neocortex, with these characteristic terminal rows which form synapses with axon initial segments, have been called axoaxonic cells (Somogyi, 1977) and we will use this term here, although in the cerebral cortex it is clear that the axoaxonic cell is the same as what was previously called the chandelier cell (Szentágothai and Arbib, 1974).

\section{Origin of GAD-immunoreactive boutons in contact with the initial segment of pyramidal neurons}

The most important finding of the present study is that almost all synaptic boutons on the axon initial segment of pyramidal neurons are GAD positive and therefore GABAergic. It is, in fact, questionable whether the non-immunoreactive boutons we studied really lack GAD. Since the proportion of GAD-positive boutons gradually decreased on the same initial segment when sections were obtained from deeper parts of the thick section, the poor penetration of antibodies is a likely explanation for the absence of staining in $8 \%$ of the boutons we studied. This is supported by the lack of any structural feature that distinguished the nonstained boutons from the GAD-positive ones; furthermore, both formed symmetrical synaptic contacts.

Our quantitative results allow us to draw certain conclusions about the transmitter of hippocampal axoaxonic cells. An individual axoaxonic cell supplies nearly $40 \%$ of all the boutons on the initial segment of one hippocampal pyramidal cell. This means that if, for example, one of the axoaxonic cells innervating each initial segment is not GABAergic, then about $40 \%$ of the synaptic terminals would not be immunoreactive for GAD. Our finding that only $8 \%$ of the boutons on the axon initial segment were not GAD positive indicates first, that the boutons of axoaxonic cells must be among the immunoreactive ones and second, that all the hippocampal axoaxonic cells are likely to contain GAD.

There are other lines of evidence for the origin from axoaxonic cells of most GAD-positive boutons in contact with the initial segment of hippocampal pyramidal cells. First, the fine structural characteristics of Golgi-impregnated axoaxonic cell boutons are the same as those of the GAD-positive boutons (monkey: Somogyi et al., 1983; cat: present study). Second, many of the GAD-positive boutons are interconnected along the axon initial segment by thin fibers in exactly the same way as the Golgiimpregnated profiles of the specialized terminal segments of identified axoaxonic cells.

Our findings in the hippocampus can be compared with studies on the visual cortex of the rat (Peters et al., 1982), where GAD-positive boutons were found in synaptic contact with axon initial segments of layer II/III pyramidal neurons. The morphological features of these boutons resemble those of Golgi-impregnated axoaxonic terminals, and this led the authors to suggest that these GAD-positive boutons might be derived from axoaxonic cells. Peters et al. (1982) also stated, but did not give any evidence, that "all terminals synapsing with the axon 

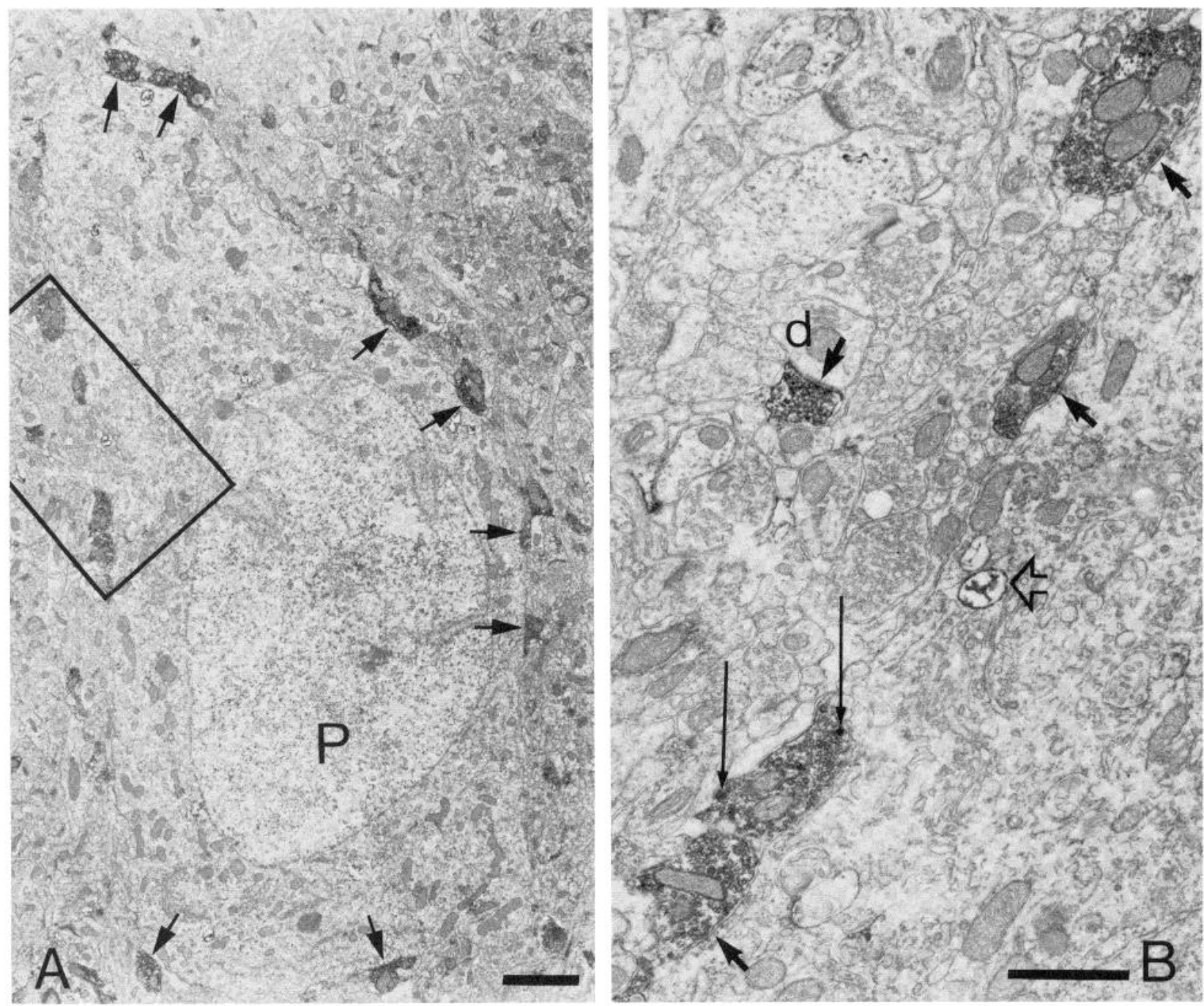

Figure 10. A pyramidal neuron $(P)$ surrounded by immunoreactive boutons (arrows). The framed area is shown in $B$, where three synaptic contacts (short arrows) are seen on the perikaryon. Large granulated vesicles (long arrows), apparently covered with reaction endproduct, have been seen rarely in some immunoreactive boutons. Reaction endproduct as a result of endogenous peroxidase activity has also been seen in vacuoles with pyramidal cell perikarya (open arrow), Small dendrites like the one here (d) received symmetrical synapses from GAD-positive boutons in all layers. Scales: $A, 2 \mu \mathrm{m} ; B, 1 \mu \mathrm{m}$.

initial segments of pyramidal cells are GAD positive." Thus, it may be concluded that there is good reason to believe that axoaxonic cells in both the cat hippocampus and the rat visual cortex contain GAD.

Although most of the boutons forming synapses on the axon initial segment are undoubtedly provided by the specialized axoaxonic interneurons, a few might originate from different sources. All identified Golgi-impregnated boutons in the present and previous studies (Somogyi et al., 1983) were found to be in contact only with axon initial segments. However, we have found two GADpositive boutons in synaptic contact with the initial segment that are also in synaptic contact with a dendrite; this may indicate that they are not the boutons of the specific axoaxonic cell but of some other GABAergic interneuron. In addition, it has been demonstrated in the hippocampus of the rat (Kosaka, 1980) that there are some boutons in asymmetrical synaptic contact with the initial segment. These boutons probably originate from different neurons, as all synaptic contacts of axoaxonic cells are of the symmetrical type. Thus, we can conclude that the initial segment of pyramidal cells in the hippocampus is largely innervated by boutons of a specific GABAergic interneuron and receives very few synapses from other neurons. In studies on the pyramidal cell initial segment in the neocortex, it has also been concluded that the great majority of synaptic boutons are derived from axoaxonic cells (Somogyi et al., 1982a).

\section{GAD-immunoreactive cell bodies}

The distribution and position of axoaxonic cells cannot be tested by immunocytochemistry alone. The immunocytochemical procedure for GAD reveals perikarya with only a little of their proximal dendrites; thus it is not possible to identify the neuron types. Similarly, in any particular area, all GAD-positive axon terminals and fibers are stained, which makes it impossible to recognize the arborizations of individual axons and the type of neuron from which they derive. We can only suggest, on the basis of comparison, that some of the small GAD- 
positive perikarya in the pyramidal cell layer might correspond to the axoaxonic cells since, in the monkey, the identified axoaxonic cells were of similar size and were found in the pyramidal cell layer (Somogyi et al., 1983). These GAD-positive cells in the cat are among the most strongly stained and were frequently seen without the use of colchicine. Their shapes were in general similar to those described by Ribak et al. (1978) in the rat hippocampus.

\section{GABAergic input to hippocampal pyramidal cells}

This study demonstrates that the same pyramidal neuron receives GAD-positive synapses on the axon initial segment, the perikaryon, the main basal and apical dendrites, and other smaller dendrites. Only the boutons on the initial segment could be shown here to originate from the axoaxonic cells; the other boutons must be provided by other neurons, probably by the other types of GAD-positive local neurons demonstrated here. Since there is much evidence that GAD is a reliable marker for GABAergic neurons (Fonnum and Storm-Mathisen, 1978), we shall assume that the presence of GAD in a bouton indicates that GABA is the transmitter.

It has often been suggested that the boutons surrounding the cell bodies of pyramidal neurons originate from GABAergic basket cells (Curtis et al. 1970, 1971; Ribak et al., 1978, 1981; Andersen et al., 1980). However, it should be emphasized that, so far, there is no evidence for the preferential or exclusive termination of a specific interneuron on the cell bodies of pyramidal cells and thus it is possible that neurons terminating on the perikaryon also supply the proximal and distal dendrites with terminals. Such a pattern of termination has recently been described for interneurons that innervate pyramidal neurons in the cat's cerebral cortex (DeFelipe and Fairén, 1982; Martin et al., 1983). There is electrophysiological evidence for the segregation of inhibitory input to different regions of the pyramidal cell (Alger and Nicoll, 1979, 1982a; Fujita, 1979; Andersen et al., 1980) and morphological evidence of many different types of interneuron (Lorente de Nó, 1934; Purpura and Pappas, 1968; Ramón y Cajal, 1968; Amaral, 1978; Tömböl et al., 1978). Accordingly, different types of interneurons may terminate on different parts of the pyramidal neuron. Since the axoaxonic cell only innervates the axon initial segment, it is clear that the GABAergic input of the pyramidal neuron comes from at least two, and possibly several, distinct interneurons.

Why does the pyramidal neuron require a segregated GABAergic input? At present it is difficult to answer this question, but the most likely explanation is that the different interneurons mediate inhibition through different pathways. Both feedback and feedforward inhibition have been reported in the hippocampus (Spencer and Kandel, 1961a; Andersen et al., 1963, 1964b, 1969; Knowles and Schwartzkroin, 1981; Alger and Nicoll, 1982a). Feedforward inhibition, part of which is mediated by GABA, has been described at the level of the dendrites and has been shown to be mediated by a set of interneurons that differs from those which mediate recurrent inhibition (Alger and Nicoll, 1982a). Recurrent inhibition is generally assumed to involve a GABAergic interneuron, such as the basket cell, which terminates on the soma (see Andersen et al., 1980; Alger and Nicoll, 1982a) but, as pointed out by Alger and Nicoll (1982b), the hyperpolarizing response of a neuron to GABA applied in the pyramidal cell layer could just as well be due to the action of GABA on the axon initial segment as to an effect on the soma. Our results raise the possibility that the GABAergic axoaxonic cell, with its relatively localized axonal field, mediates recurrent inhibition whereas other types of interneuron, like the basket cell with its more extensive arborization (Lorente de Nó, 1934; Ramón y Cajal, 1968), might mediate feedforward inhibition.

\section{Possible functional implications of a massive GABAergic input to the axon initial segment}

The remarkable fact that one type of interneuron provides almost all the synaptic input to the axon initial segment, the site where the action poteritial is believed to originate (Spencer and Kandel, 1961b), and that the transmitter of this interneuron is GABA, must have important functional implications. However, until it is known what action GABA has on the electrical properties of the initial segment, we can only speculate about the meaning of our morphological observations. Electrophysiological studies on hippocampal slices have already shown that the actions of GABA are complex, since not only the somatic region of the pyramidal neuron but also its apical and basal dendrites are sensitive to GABA; increases in membrane conductance occur in both the soma and the dendrites: this leads to hyperpolarization in the soma and depolarization in the dendrites (Alger and Nicoll, 1979, 1982b; Andersen et al. 1980, 1982; Jahnsen et al, 1981; Thalmann et al., 1981). If the membrane of the initial segment also responds to GABA with increased conductance, this would have a powerful effect on the output from the pyramidal cell; clearly, electrophysiological experiments are now required to determine what this effect will be. As pointed out above, it cannot be excluded that the effects of GABA applied in the pyramidal cell layer and hitherto attributed to its action on the soma might also reflect its action on the axon initial segment.

Inhibition of pyramidal neurons is generally believed to be the main action of interneurons in the hippocampus (Andersen, 1975), but the large variety of such interneurons (Amaral, 1978) makes it difficult to draw the conclusion that all interneurons, including the GABAergic axoaxonic cell, are inhibitory. Nevertheless, there are some observations which indicate that the basket cell cannot be responsible for all inhibitory effects. First, it has been found that the inhibitory postsynaptic potentials in pyramidal cells of the hippocampus of the newborn kitten are almost identical to those in the adult (Purpura et al., 1968), whereas axosomatic synapses (of presumed basket cclls) are almost absent at this age (Schwartz et al., 1968). Second, as mentioned above, inhibition at the level of the dendrites is mediated by a different set of interneurons from those which mediate inhibition in the somatic region (Alger and Nicoll, 1982a). Third, there is evidence that inhibition of pyramidal neurons can be mediated by an interneuron distinct from the basket cell (Schwartzkroin and Mathers, 1978; Knowles and Schwartzkroin, 1981). The GABAergic axoaxonic cell is clearly one pos- 
sible candidate for such an inhibitory interneuron in the hippocampus. Two features of the morphology of the axoaxonic cell could be of functional importance in the way such inhibition is distributed: first, each individual terminal bouton row comprises a relatively large proportion (up to nearly $40 \%$ ) of the synapses on an individual initial segment and, second, a single axoaxonic cell innervates the initial segments of several hundred pyramidal neurons (Somogyi et al., 1983). Thus, axoaxonic cells might play a key role in synchronizing the output of a large number of pyramidal neurons.

Whatever the action of GABA on the initial segment turns out to be, it can already be concluded from the morphological evidence alone that the highly strategic location of GABAergic synapses of a specific interneuron at this site has pharmacological implications. Drugs that block the release or action of GABA at these synapses will directly influence the output of the pyramidal cells, just as will drugs that mimic or potentiate the actions of GABA. The initial segment is likely, therefore, to be one of the targets of those convulsant and antiepileptic drugs whose actions are thought to be related to GABAergic transmission (Schwartzkroin and Prince, 1980; Morselli et al., 1981).

\section{References}

Alger, B. E., and R. A. Nicoll (1979) GABA-mediated biphasic responses in hippocampus. Nature 281: 315-317.

Alger, B. E., and R. A. Nicoll (1982a) Feed-forward dendritic inhibition in rat hippocampal pyramidal cells studied in vitro. J. Physiol. (Lond.) 328: 105-123.

Alger, B. E., and R. A. Nicoll (1982b) Pharmacological evidence for two kinds of GABA receptor on rat hippocampal pyramidal cells studied in vitro. J. Physiol. (Lond.) 328: 125-141.

Amaral, D. G. (1978) A Golgi study of cell types in the hilar region of the hippocampus in the rat. J. Comp. Neurol. 182: 851-914.

Andersen, P. (1975) Organization of hippocampal neurons and their interconnections. In The Hippocampus. Vol. 1: Structure and Development, R. L. Isaacson and K. H. Pribham, eds., pp. 155-175, Plenum Press, New York.

Andersen, P. (1976) Some properties of synapses near to and far from the soma of hippocampal pyramids. Exp. Brain Res. (Suppl.) 1: 202-206.

Andersen, P., J. C. Eccles, and Y. Løyning (1963) Recurrent inhibition in the hippocampus with identification of the inhibitory cell and its synapses. Nature 198: 540-542.

Andersen, P., J. C. Eccles, and Y. Løyning (1964a) Location of postsynaptic inhibitory synapses on hippocampal pyramids. J. Neurophysiol. 27: 592-607.

Andersen, P., J. C. Eccles, and Y. Løyning (1964b) Pathway of postsynaptic inhibition in the hippocampus. J. Neurophysiol. 27: 608-619.

Andersen, P., G. N. Gross, T. Lømo, and O. Sveen (1969) Participation of inhibitory and excitatory interneurones in the control of hippocampal cortical output. In The Interneuron, M. A. B. Brazier, ed., pp. 415-465, University of California Press, Berkeley.

Andersen, P., R. Dingledine, L. Gjerstad, I. A. Langmoen, and A. M. Laursen (1980) Two different responses of hippocampal pyramidal cells to application of gamma-aminobutyric acid. J. Physiol. (Lond.) 305: 279-296.

Andersen, P., B. Bie, and T. Ganes (1982) Distribution of GABA sensitive areas on hippocampal pyramidal cells. Exp. Brain Res. 45: 357-363.

Barber, R., and K. Saito (1976) Light microscopic visualization of GAD and GABA-T in immunocytochemical preparations of rodent CNS. In Gaba in Nervous Syslem Function, E. Roberts, T. N. Chase, and D. B. Tower, eds., pp. 113-132, Raven Press, New York.

Ben-Ari, Y., K. Krnjević, R. J. Reiffenstein, and W. Reinhardt (1981) Inhibitory conductance changes and action of $\gamma$-aminobutyrate in rat hippocampus. Neuroscience $6: 2445-2463$.

Biscoe, T. J., and D. W. Straughan (1966) Micro-electrophoretic studies of neurones in the cat hippocampus. J. Physiol. (Lond.) 183: 341-359.

Bolam, J. P., P. Somogyi, H. Takagi, I. Fodor, and A. D. Smith (1983) Localization of substance P-like immunoreactivity in neurons and nerve terminals in the neostriatum of the rat: $A$ correlated light and electron microscopic study. J. Neurocytol. 12: 325-344.

Curtis, D. R., D. Felix, and H. McLennan (1970) GABA and hippocampal inhibition. Br. J. Pharmacol. 40:881-883.

Curtis, D. R., A. W. Duggan, D. Felix, G. A. R. Johnston, and H. McLennan (1971) Antagonism between bicuculline and GABA in the cat brain. Brain Res. 33: 57-73.

DeFelipe, J., and A. Fairén (1982) A type of basket cell in superficial layers of the cat visual cortex. A Golgi-electron microscope study. Brain Res. 244: 9-16.

Fairén, A., and F. Valverde (1980) A specialized type of neuron in the visual cortex of cat. A Golgi and electron microscopic study of chandelier cells. J. Comp. Neurol. 194: 761-779.

Fairén, A., A. Peters, and J. Saldanha (1977) A new procedure for examining Golgi impregnated neurons by light and electron microscopy. J. Neurocytol. 6: 311-337.

Fonnum, F., and J. Storm-Mathisen (1978) Localization of GABA-ergic neurons in the CNS. In Handbook of Psychopharmacology, L. L. Iversen, S. D. Iversen, and S. H. Snyder, eds., Vol. 9, pp. 357-401, Plenum Press, New York.

Fujita, Y. (1979) Evidence for the existence of inhibitory postsynaptic potentials in dendrites and their functional significance in hippocampal pyramidal cells of adult rabbits. Brain Res. 175: 59-69.

Jahnsen, H., and A. M. Mosfeldt-Laursen (1981) The effects of a benzodiazepine on the hyperpolarizing and the depolarizing responses of hippocampal cells to GABA. Brain Res. 207: 214-217.

Kandel, E. R., W. A. Spencer, and F. J. Brinley (1961) Electrophysiology of hippocampal neurons. I. Sequential invasion and synaptic organization. J. Neurophysiol. 24: 225-242.

Knowles, W. D., and P. A. Schwartzkroin (1981) Local circuit synaptic interactions in hippocampal brain slices. J. Neurosci. 1: $318-322$.

Kosaka, T. (1980) The axon initial segment as a synaptic site: Ultrastructure and synaptology of the initial segment of the pyramidal cell in the rat hippocampus (CA3 region). J. Neurocytol. 9: 861-882.

Lorente de Nó, R. (1934) Studies on the structure of the cerebral cortex. II. Continuation of the study of the ammonic system. J. Psychol. Neurol. (Lpz.) 46: 113-177.

Martin, K. A. C., P. Somogyi, and D. Whitteridge (1983) Physiological and morphological properties of identified basket cells in the cat's visual cortex. Exp. Brain Res., in press.

Morselli, P. L., K. G. Lloyd, W. Loscher, B. Meldrum, and E. H. Reynolds (1981) Neurotransmitters, Seizures and Epilepsy, Raven Press, New York.

Palay, S. L., C. Sotelo, A. Peters, and P. M. Orkand (1968) The axon hillock and the initial segment. J. Cell Biol. 38: 193-201.

Peters, A., C. C. Proskauer, and C. E. Ribak (1982) Chandelier cells in rat visual cortex. J. Comp. Neurol. 206: 397-416.

Purpura, D. P., and G. D. Pappas (1968) Structural characteristics of neurons in the feline hippocampus during postnatal ontogenesis. Exp. Neurol. 22: 379-393.

Purpura, D. P., S. Prelevic, and M. Santini (1968) Postsynaptic potentials and spike variations in the feline hippocampus 
during postnatal ontogenesis. Exp. Neurol. 22: 408-422.

Rumón y Cajal, S. (1911) Histologie du Systeme Nerveux de l'Homme et des Vertebres, Malonie, Paris.

Ramón y Cajal, S. (1968) The Structure of Ammon's Horn, L. M. Kraft, transl., Charles C Thomas, Springfield, IL.

Reynolds, E. S. (1963) The use of lead citrate at high pH as an electron opaque stain in electron microscopy. J. Cell Biol. 17: 208-212.

Ribak, C. E. (1978) Aspinous and sparsely-spinous stellate neurons in the visual cortex of rats contain glutamic acid decarboxylase. J. Neurocytol. 7: 461-478.

Ribak, C. E., J. E. Vaughn, and K. Saito (1978) Immunocytochemical localization of glutamic acid decarboxylase in neuronal somata following colchicine inhibition of axonal transport. Brain Res. 140: 315-332.

Ribak, C. E., J. E. Vaughn, and R. P. Barber (1981) Immunocytochemical localization of GABAergic neurones at the electron microscopical level. Histochem. J. 13: 555-582.

Saito, K., J. -Y. Wu, T. Matsuda, and E. Roberts (1974) Immunochemical comparison of vertebrate glutamate decarboxylase. Brain Res. 65: 277-285.

Schwartz, I. R., G. D. Pappas, and D. P. Purpura (1968) Fine structure of neurons and synapses in the feline hippocampus during postnatal ontogenesis. Exp. Neurol. 22: 394-407.

Schwartzkroin, P. A., and L. H. Mathers (1978) Physiological and morphological identification of a nonpyramidal hippocampal cell type. Brain Res. 157: 1-10.

Schwartzkroin, P. A. and D. A. Prince (1980) Changes in excitatory and inhibitory synaptic potentials leading to epileptogenic activity. Brain Res. 183: 61-76.

Sofroniew, M. V., and U. Schrell (1982) Long term storage and repeated use of diluted antisera in glass staining jars for increased sensitivity, reproducibility, and convenience of single and two-color light microscopic immunocytochemistry. J. Histochem. Cytochem. 30: 504-511.

Somogyi, P. (1977) A specific 'axo-axonal' interneuron in the visual cortex of the rat. Brain Res. 136: 345-350.

Somogyi, P. (1979) An interneuron making synapses specifically on the axon initial segement (AIS) of pyramidal cells in the cerebral cortex. J. Physiol. (Lond.) 296: 18-19P.

Somogyi, P., and H. Takagi (1982) A note on the use of picric acid-paraformaldehyde-glutaraldehyde fixative for correlated light and electron microscopic immunocytochemistry. Neuroscience $7:$ : 1779-1783.

Somogyi, P., A. J. Hodgson, and A. D. Smith (1979) An approach to tracing neuron networks in the cerebral cortex and basal ganglia. Combination of Golgi staining, retrograde transport of horseradish peroxidase and anterograde degeneration of synaptic boutons in the same material. Neuroscience 4: 1805-1852.

Somogyi, P., T. F. Freund, N. Halasz, and Z. F. Kisvarday
(1981) Selectivity of neuronal $\left[{ }^{3} \mathrm{H}\right] \mathrm{GABA}$ accumulation in the visual cortex as revealed by Golgi staining of the labelled neurons. Brain Res. 225: 431-436.

Somogyi, P., T. F. Freund, and A. Cowey (1982a) The axoaxonic interneuron in the cerebral cortex of the rat, cat and monkey. Neuroscience 7: 2577-2608.

Somogyi, P., J. V. Priestley, A. C. Cuello, A. D. Smith, and H. Takagi (1982b) Synaptic connections of enkephalin-immunoreactive nerve terminals in the neostriatum: A correlated light and electron microscopic study. J. Neurocytol. 11: 779807.

Somogyi, P., J. V. Priestley, A. C. Cuello, A. D. Smith, and J. P. Bolam (1982c) Synaptic connections of substance P-immunoreactive nerve terminals in the substantia nigra of the rat: A correlated light- and electron-microscopic study. Cell Tissue Res. 223: 469-486.

Somogyi, P., M. G. Nunzi, A. Gorio, and A. D. Smith (1983) A new type of specific interneuron in the monkey hippocampus forming synapses exclusively with the axon initial segments of pyramidal cells. Brain Res. 259: 137-142.

Spencer, W. A., and E. R. Kandel (1961a) Hippocampal neuron responses to selective activation of recurrent collaterals of hippocampofugal axons. Exp. Neurol. 4: 149-161.

Spencer, W. A., and E. R. Kandel (1961b) Electrophysiology of hippocampal neurons. III. Firing level and time constant. J. Neurophysiol. 24: 260-271.

Storm-Mathisen, J. (1977) Localization of transmitter candidates in the brain: the hippocampal formation as a model. Prog. Neurobiol. 8: 119-181.

Szentágothai, J., and M. A. Arbib (1974) Conceptual models of neural organization. Neurosci. Res. Program Bull. 12: 307510.

Takagi, H., P. Somogyi, J. Somogyi, and A. D. Smith (1983) Fine structural studies on a type of somatostatin-immunoreactive neuron and its synaptic connections in the rat neostriatum: A correlated light and electron microscopic study. J. Comp. Neurol. 214: 1-16.

Thalmann, R. H., E. J. Peck, and G. F. Ayala (1981) Biphasic response of hippocampal pyramidal neurons to GABA. Neurosci. Lett. 21: 319-324.

Tömböl, T., G. Somogyi, and F. Hajdu (1978) Golgi Study on cat hippocampal formation. Anat. Embryol. 153: 331-350.

Wu, J. -Y., 'I. Matsuda, and E. Roberts (1973) Purification and characterization of glutamate decarboxylase from mouse brain. J. Biol. Chem. 248: 3029-3034.

Wu, J. -Y., C. -T. Lin, T. S. Brandon, H. Mohler, and J. G. Richards (1982) Regulation and immunocytochemical characterization of glutamic acid decarboxylase. In Cytochemical Methods in Neuroanatomy, V. Chan-Palay and S. L. Palay, eds., pp. 279-296, Alan R. Liss, Inc., New York. 